\title{
Clarification of the Necessary Value of Surface Roughness for Developing Luster on an AZ31 Magnesium Alloy Surface with or without Acid Aqueous Solution Treatment
}

\author{
Miyoshi Ohara $^{1}$, Haruo Okahara ${ }^{1}$, Yorinobu Takigawa ${ }^{2}$ and Kenji Higashi ${ }^{2}$ \\ ${ }^{1}$ Research and Development Department, Kasatani Co., Ltd., Osaka 532-0036, Japan \\ ${ }^{2}$ Department of Materials Science, Graduate School of Engineering, Osaka Prefecture University, Sakai 599-8531, Japan
}

\begin{abstract}
To shorten the press forming and surface treatment process for AZ31 magnesium alloy by eliminating the need for mechanical polishing of the press-formed surface, we determined the necessary value of surface roughness, $R a$, for developing a luster on surface with or without acid aqueous solution treatment. The target value for the gloss of AZ31 magnesium alloys was set to be that of the surface after mechanical polishing by using emery paper \#2000. To achieve this gloss solely by mechanical polishing without acid aqueous solution treatment, the surface roughness, $R a$, had to be less than $0.2 \mu \mathrm{m}$. If the acid aqueous solution treatment was applied to the mechanically polished surface, the necessary surface roughness, $R a$, before the treatment was $1.5 \mu \mathrm{m}$. The increase in gloss as a result of acid aqueous solution treatment results from smoothing of small surface convexo-concave features measuring less than $0.2 \mu \mathrm{m}$. Because the surface roughness, $R a$, of articles press-formed by using 100,000 times square-cup drawings was $0.3 \mu \mathrm{m}$, the mechanical polishing stage could be eliminated from the process for developing a luster, and the acid aqueous solution treatment could be applied directly. [doi:10.2320/matertrans.MC2007103]
\end{abstract}

(Received October 26, 2007; Accepted December 27, 2007; Published April 25, 2008)

Keywords: AZ31 magnesium alloy, gloss, surface roughness, acid aqueous solution treatment, mechanical polishing, press working, surface treatment

\section{Introduction}

Metallic materials are frequently used in the chassis of laptop computers and cellular phones. The surfaces of such chassis are characterized by their luster rather then by any geometrical figure. Recently, chassis for laptop computers and cellular phones have been developed that make use of magnesium alloys. However, painting is the only practical surface treatment for such parts. The purpose of most studies on surface treatments of magnesium alloys, such as chemical treatment, ${ }^{1,2)}$ anodizing ${ }^{3-6)}$ or evaporation coating, ${ }^{7)}$ is to improve the corrosion resistance and paint adhesion of the alloys. Any luster is usually lost as a result of the application of such surface treatments. Therefore, a surface treatment for polishing magnesium alloys to develop a luster has been developed. In this method, ${ }^{8)}$ the surface is first mechanically polished and a colorless clear film is then applied to the surface so that the luster of the magnesium alloys is retained. The mechanical polishing stage is an integral part of this surface treatment.

It has been pointed out that the excellent surface features of hot-rolled AZ31 magnesium alloys are kept after the press working as it is, and a mass-production method, the 100,000 times square-cup drawing method, has been developed. ${ }^{9-12)}$ This method is expected to shorten the production of magnesium parts, which is a necessary prerequisite for using AZ31 magnesium alloys in the production of chassis.

We have developed an acid aqueous solution treatment for producing a luster on AZ31 magnesium alloy. ${ }^{13,14)}$ However the relationship between the condition of the surface before and after the acid aqueous solution treatment and the luster that is developed has not been studied.

We determined the value of surface roughness, $R a$, which is necessary for developing a luster on AZ31 magnesium alloy surface with or without acid aqueous solution treatment, with the aim of shortening the press-forming and surfacetreatment process by eliminating the need for mechanical polishing of the press-formed surface.

\section{Experimental Procedure}

Hot-rolled magnesium alloy (AZ31B) was used in this study. The surface oxide layer was removed by using a grinder. The thickness of the plate was $0.8 \mathrm{~mm}$. Specimens measuring $50 \mathrm{~mm}$ wide by $50 \mathrm{~mm}$ long were cut from the plate, unidirectionally polished, and subjected to acid aqueous solution treatment. Details of the polishing method and the conditions for acid aqueous solution treatment are summarized in Tables 1 and 2, respectively. The specimens were stored in a vacuum desicator until the measurements were made. The surface roughness, $R a$ was measured by using a contact surface-roughness measurement tester. The measured lines were $4 \mathrm{~mm}$ in length perpendicular to the direction of polishing. The measurements ware conducted at two points near the centers of the specimens and the resulting values were averaged. The gloss was measured by using a gloss meter. Figure 1 is a conceptual diagram of the gloss meter. The angles $(\theta)$ of incidence and reflection were both

Table 1 The method for mechanical polishing.

\begin{tabular}{ll}
\hline Used tool \\
\hline No polish \\
Waterproof abrasive paper \#220 \\
Waterproof abrasive paper \#400 \\
Waterproof abrasive paper \#600 \\
Waterproof abrasive paper \#2000 \\
Emery paper \#2000 \\
Buffing \\
\hline
\end{tabular}


Table 2 The acid aqueous solution treatment conditions.

\begin{tabular}{ll}
\hline Nitric acid & $0.5 \mathrm{~mol} \mathrm{dm}^{-3}$ \\
Adipic acid & $0.01 \mathrm{~mol} \mathrm{dm}^{-3}$ \\
Deionized water & Balance \\
\hline Temperature & $278 \mathrm{~K}$ \\
Ultrasonic wave & $28 \mathrm{kHz}$ \\
Time & $30 \mathrm{~s}$ \\
\hline
\end{tabular}

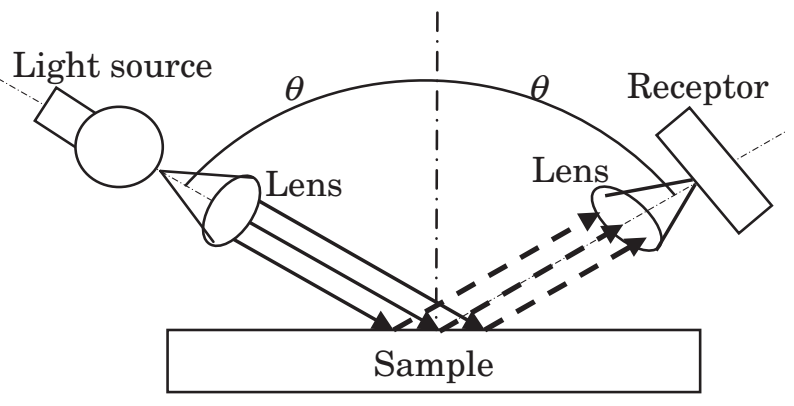

Fig. 1 A conceptual diagram of the gloss meter.

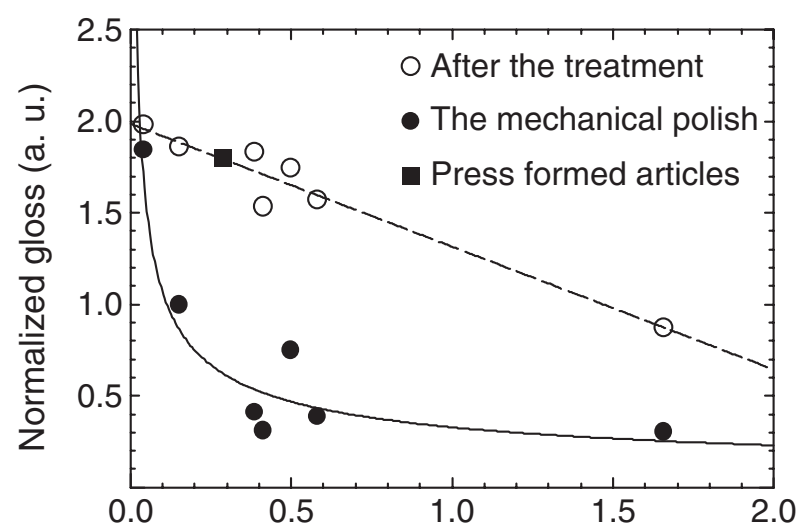

Original roughness, $R a / \mu \mathrm{m}$

Fig. 2 The relationship between the original roughness, $R a$, and the normalized gloss in AZ31 magnesium alloy. Original roughness: the surface roughness, $R a$, before the acid aqueous solution treatment.

$60^{\circ}$. The gloss meter was calibrated by using a polished piece of black glass as a primary standard. The directions of the measurement were perpendicular and parallel to the direction of polishing, and the resulting values of gloss were averaged. The target value for the gloss was set at that shown by the surface of AZ31 magnesium alloys after mechanical polishing with emery paper \#2000. The normalized gloss value was calculated as the ratio between the value of the gloss from the specimen and the target value of the gloss from a specimen polished with emery paper \#2000.

Scanning electron microscopy (SEM) was used to investigate the surface morphology.

\section{Results and Discussion}

Figure 2 shows the relationship between the original roughness, $R a$, and the normalized gloss of AZ31 magnesium
Table 3 The surface roughness, $R a$, before and after acid aqueous solution treatment.

\begin{tabular}{ccc}
\hline $\begin{array}{c}\text { The method for } \\
\text { mechanical polishing }\end{array}$ & $\begin{array}{c}\text { Before } \\
R a / \mu \mathrm{m}\end{array}$ & $\begin{array}{c}\text { After } \\
R a / \mu \mathrm{m}\end{array}$ \\
\hline $\begin{array}{c}\text { Waterproof abrasive } \\
\text { paper \#220 } \\
\begin{array}{c}\text { Waterproof abrasive } \\
\text { paper \#400 }\end{array}\end{array}$ & 1.66 & 1.30 \\
$\begin{array}{c}\text { Waterproof abrasive } \\
\text { paper \#600 } \\
\begin{array}{c}\text { Waterproof abrasive } \\
\text { paper \#2000 } \\
\text { No polish }\end{array}\end{array}$ & 0.58 & 0.31 \\
\hline
\end{tabular}

alloys. The original roughness, $R a$, was the surface roughness, $R a$, before applying acid aqueous solution treatment. In the mechanically polished specimen, the normalized gloss increased exponentially with the decreasing surface roughness, $R a$. The target value of gloss was achieved when the surface roughness, $R a$, was less than $0.2 \mu \mathrm{m}$. The normalized gloss was constant for surface roughness values, $R a$, of more than $0.4 \mu \mathrm{m}$. The normalized gloss increased sharply when the surface roughness, $R a$, became less than $0.2 \mu \mathrm{m}$. This result agrees well with results reported for aluminum alloys and titanium. ${ }^{15,16)}$

When the mechanically polished surface was subjected to the acid aqueous solution treatment, the normalized gloss increased in proportion to the decrease in the surface roughness, $R a$. The target value of gloss was achieved when the original roughness, $R a$, was less than $1.5 \mu \mathrm{m}$. The normalized gloss was more than 1.5 when the original roughness, $R a$, was less than $0.7 \mu \mathrm{m}$. When the acid aqueous solution treatment was applied, the target gloss value could be achieved even in the presence of surface roughness, unlike, the case in the absence of acid aqueous solution treatment.

Table 3 shows the surface roughness, $R a$, before and after the acid aqueous solution treatment. The normalized gloss increased on mechanical polishing when the surface roughness, $R a$, was less than $0.2 \mu \mathrm{m}$. However, when the acid aqueous solution treatment was applied to the mechanically polished surface, the normalized gloss was above the target value when the surface roughness, $R a$, after acid aqueous solution treatment was $1.3 \mu \mathrm{m}$. We, therefore, postulate that the increase in normalized gloss is not solely a function of the surface roughness, $R a$. Hirono et al. have reported that the relationship between the values of the gloss and the surface roughness is not universal and that the number microscopic convexo-concave features are very limited when the value of the gloss is high. ${ }^{17}$ )

We observed the presence of microscopic convexoconcave feature in the profiles of AZ31 magnesium alloys. Figure 3(a) shows the profile of specimens polished only by using emery paper \#2000. Figure 3(b) shows the profile of specimens polished by using emery paper \#2000 and then subjected to the acid aqueous solution treatment. Many convexo-concave features measuring about $0.2 \mu \mathrm{m}$ can be observed in Fig. 3(a), whereas in Fig. 3(b), convexo-concave features of about $0.2 \mu \mathrm{m}$ are scarcely observable. The acid 


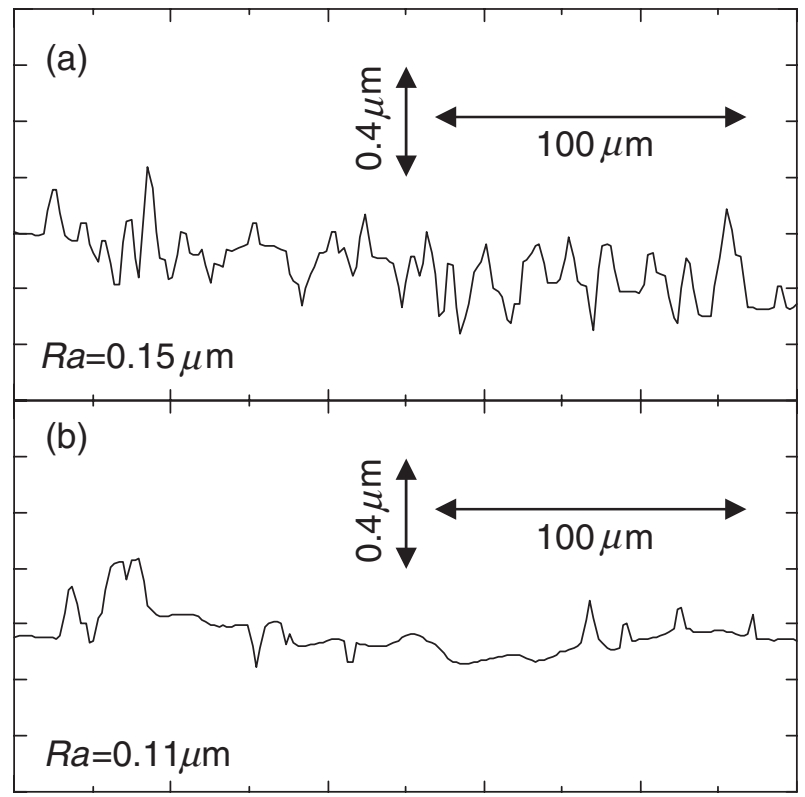

Fig. 3 (a) Profiles of specimens polished by using emery paper \#2000. (b) Profiles of specimens polished by using emery paper \#2000 and then subjected to acid aqueous solution treatment.

aqueous solution treatment therefore smoothes out convexoconcave features measuring about $0.2 \mu \mathrm{m}$. These results suggest that the increase in the normalized gloss was due to smoothing of $0.2 \mu \mathrm{m}$ convexo-concave features and that the relatively high surface roughness, $R a$, after the acid aqueous solution treatment was due to residual deep scratches produced by the mechanical polishing.

Figure 4 shows the SEM image of the surface. The surface before the acid aqueous solution treatment showed scratched from polishing and microscopic scratches. After the acid aqueous solution treatment, a smoothed surface and a mesh structure measuring about $50 \mathrm{~nm}$ were observed. ${ }^{14)}$ From these result, we conclude that surface convexo-concave features measuring less than about $0.2 \mu \mathrm{m}$ were smoothed out by the acid aqueous solution treatment, resulting in an increasing in specular reflection.

Okahara et al..$^{9-12)}$ have developed a press-forming die to control surface flaws after forming, and have examined mass production by 100,000 times square-cup drawings in AZ31 magnesium alloys. The side surface of the press-formed article showed no flaws, and the surface roughness, $R a$, was $0.3 \mu \mathrm{m}$, which was almost the same as that of the top surface. The acid aqueous solution treatment was applied to the pressformed article. Figure 5 shows the photographs taken before and after the acid aqueous solution treatment of an article formed by 100,000 times square-cup drawings. The surface was shiny after the acid aqueous solution treatment. The result of the normalized gloss after the acid aqueous solution treatment is also plotted in Fig. 2. The results were very similar to those obtained from a surface subjected to mechanical polishing and the acid aqueous solution treatment. These results show that the acid aqueous solution treatment can be applied directly to a press-formed surface without a mechanical polishing process, resulting in a shortening of the overall production process.
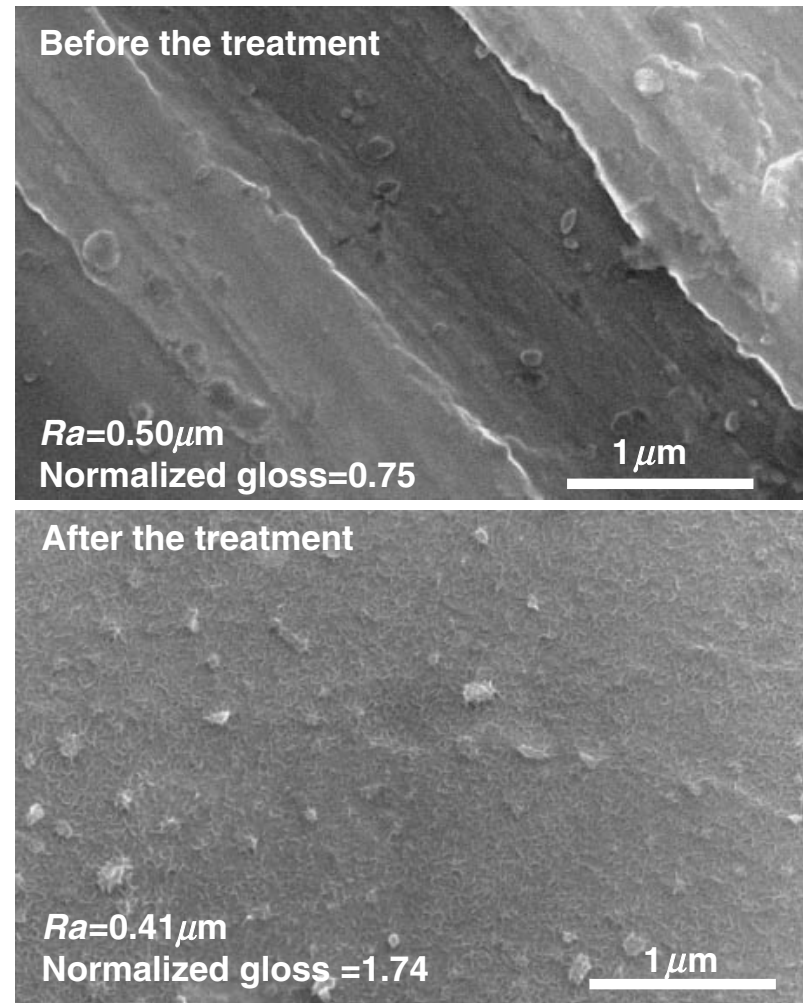

Fig. 4 SEM images of specimens surfaces before and after the acid aqueous solution treatment.

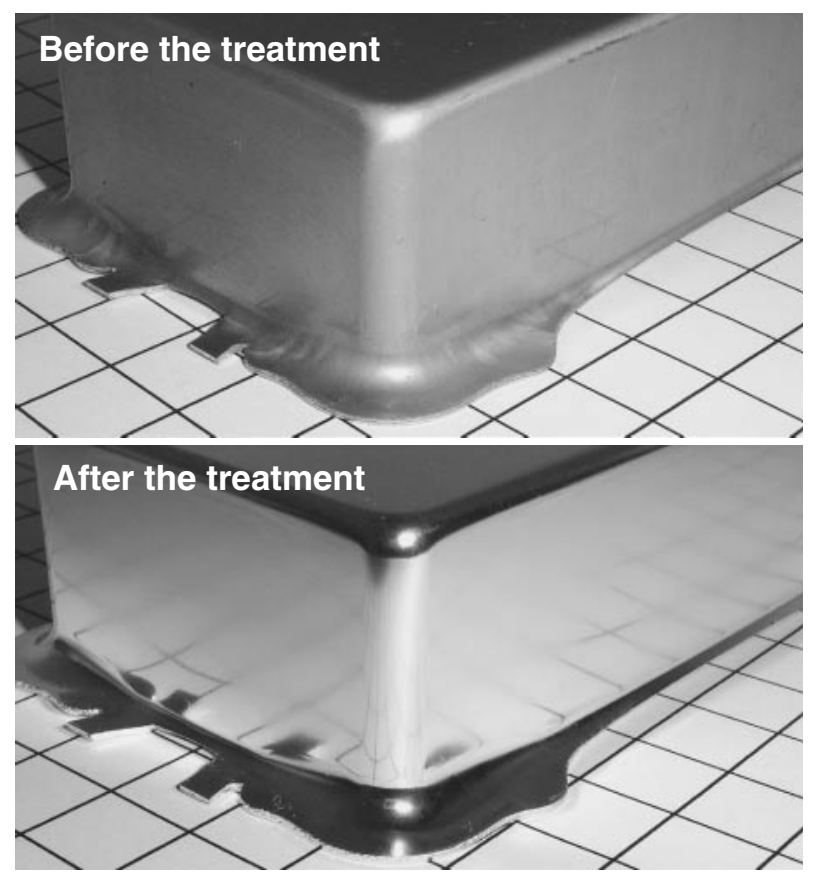

Fig. 5 Photographs taken before and after acid aqueous solution treatment of articles formed by 100,000 times square-cup drawings.

\section{Conclusions}

We determined the value of surface roughness, $R a$, necessary for developing the luster of AZ31 magnesium alloy surface with or without acid aqueous solution treatment. The following results were obtained. 
(1) When the specimen was polished by using emery paper \#2000, the surface roughness, $R a$, was less than $0.2 \mu \mathrm{m}$ : the resulting level of the gloss was set at the target value for gloss in present study.

(2) When an acid aqueous solution treatment was applied to the mechanically polished surface, the necessary surface roughness, $R a$, before acid aqueous solution treatment was $1.5 \mu \mathrm{m}$. The increase in gloss resulting from the acid aqueous solution treatment was explained in terms of smoothing of small surface convexoconcave features measuring less than $0.2 \mu \mathrm{m}$.

(3) The surface roughness, $R a$, of our press-formed articles produced by 100,000 times square-cup drawings was $0.3 \mu \mathrm{m}$. A luster could be applied to such surfaces solely by means of acid aqueous solution treatment, with no mechanical polishing being necessary. As the result, the overall production process can be shortened.

\section{REFERENCES}

1) S. Sekiguchi, C. Otani and M. Takaya: J. JILM 56 (2006) 156-161.

2) H. Umehara, M. Takaya and Y. Kojima: J. JILM 50 (2000) 109-115.
3) S. Ono: Journal of The Surface Finishing Society of Japan 53 (2002) 166-171.

4) S. Ono, H. Kijima and M. Masuko: Journal of The Surface Finishing Society of Japan 53 (2002) 406-412.

5) M. Hara, K. Matsuda, W. Yamauchi, M. Sakaguchi, T. Yoshikata, Y. Takigawa and K. Higashi: Mater. Trans. 47 (2006) 1013-1019.

6) N. Hara, Y. Kobayashi, D. Kagaya and N. Akao: Corrosion Science 49 (2007) 166-175.

7) A. Yamamoto and H. Tubakino: Materia Japan 43 (2004) 287-292.

8) M. Kakizaki: Handbook of Advanced Magnesium Technology (Kallos Publishing, 2000) 399-400.

9) H. Okahara, M. Ohara, Y. Takigawa and K. Higashi: Mater. Trans. 47 (2006) 954-958.

10) T. Kumagai, K. Shimamura, H. Okahara, Y. Takigawa and K. Higashi: Mater. Trans. 47 (2006) 1008-1012.

11) E. Goto, T. Kachi, H. Okahara, Y. Takigawa and K. Higashi: Mater. Trans. 47 (2006) 1782-1787.

12) J. Sasaya, H. Okahara, M. Yano, M. Shirakawa and K. Higashi: Sokeizai 47, No. 5 (2006) 30-34.

13) H. Okahara: ALUTOPIA 33, No. 2 (2003) 21-26.

14) M. Ohara, H. Okahara and K. Higashi: Journal of The Surface Finishing Society of Japan 56 (2005) 698-699.

15) M. Yonehara, S. Kumai, H. Isono, T. Sugibayashi and N. Igata: J. JILM 56 (2006) 429-434.

16) M. Yonehara, K. Kihara, H. Isono, T. Sugibayashi and N. Igata: J. JILM 55 (2005) 668-672.

17) M. Hirono and K. Tsunoda: J. JILM 35 (1985) 581-587. 